\title{
RESEARCH, TECHNOLOGY FRONTIER AND PRODUCTIVITY GROWTH
}

\author{
Patricio PÉREZ - Marta BENGOA - Adolfo C. FERNÁNDEZ
}

(Received: 8 March 2013; revision received: 4 February 2014; accepted: 15 October 2014)

\begin{abstract}
This paper uses the Jones (1995) framework to examine the contribution of imitation activities and innovative research effort on productivity growth for the US and some European leading economies. We carry out a comparative analysis for the last 50 years, with two model specifications, assuming country differences in the parameters associated with R\&D effort. In the first one, the technological frontier position is determined by the country with the highest productivity, the United States. Alternatively, in the second specification, we alter the definition of the technological frontier, allowing it to transcend the leader. The empirical analysis leads to very different outcomes. The first specification estimation, using GMM techniques, indicates that American researchers are more technology growth enhancing than their European counterparts. In contrast, the results obtained for the second, using Kalman's filter, show that when using an alternative definition of technological frontier, it is possible to observe a boost in innovation that reduces the dispersion among countries. Then, the leading European countries can take advantage; in this case, Germany exhibits the best performance, followed by the US.
\end{abstract}

Keywords: productivity growth, innovation, technology frontier, Kalman's filter

JEL classification indices: E17, O4, O33

Patricio Pérez, Professor of Applied Economics at the Department of Economics, University of Cantabria, Santander, Spain. E-mail: patricio.perez@unican.es

Marta Bengoa, Director Graduate Program Economics, Colin Powell School for Civic and Global Leadership. City University of New York at City. E-mail: mbengoa@ccny.cuny.edu

Adolfo C. Fernández, corresponding author. Director at the Centro Asociado UNED-Cantabria, Professor of Applied Economics at the Department of Economics, University of Cantabria, Santander, Spain. E-mail: adolfocosme.fernandez@unican.es 


\section{INTRODUCTION}

Technological progress explains much of the increase in per capita income (Solow 1957; Griliches 1994). Technological improvements and increasing efficiency are two of the main variables that contribute to productivity growth. However, the foundations of technological improvements - as Eaton - Kortum (1996) pointed out - and how they spread across countries are still a matter of study. The research and development process, its implementation and adoption - that increase technological progress - depend on the capabilities and efforts within industries. It also depends on the cooperation across sectors, and it is also influenced by other factors such as education, infrastructure, development of the financial system, entrepreneur culture, market conditions, and access to physical resources or location advantages.

The literature provides empirical evidence about two types of research activities: pure innovation or the adaptation of technology discovered elsewhere (Griffith et al. 2004). The most recent studies focus on the disparities observed among countries in terms of access to knowledge and its effects on economic growth and productivity (Barro 2001; Benhabid - Spiegel 2005; Ha - Howitt 2006; Ciccone - Papaioannou 2009; Galor 2010; Astorga et al. 2011). ${ }^{1}$ The recent works that have quantified the importance of international technology diffusion, as the ones by Strulik (2005), Vandenbussche et al. (2006), and Aghion - Howitt (2009), emphasise the role of infrastructure.

The present paper concentrates on disentangling the effects of imitative and innovative research. ${ }^{2}$ We have adapted a version of Jones' (1995) growth model with the aim of comparing international patterns of technical progress. We present an empirical framework in which innovation and technology transfer provide two potential sources of productivity growth, for countries typically leaders in inventing and re-creating technology.

The proposed scenario shows how a technological improvement may result from the combination of innovation activities and the adaptation of the technology produced elsewhere. This improvement would make the technological frontier expand. Our main goal will be testing how these determinants affect productivity

1 These studies were inspired by other seminal papers that analysed the extent of the impact of technology innovation on productivity growth (Nelson - Phelps 1966; Romer 1990; Grossman - Helpman 1991; Aghion - Howitt 1992; Mankiw et al. 1992; Caballero - Jaffe 1993; Coe - Helpman 1995).

2 Some other authors referred to the concepts of exploration and exploitation in product innovation (introduced by Levinthal - March 1981; Tushman - Anderson 1986 and more recently by Fagiolo - Dosi 2003; Lazer - Friedman 2007) as possible extensions of the process of imitation and innovation. 
growth when assuming that the US economy is the leader, and then specify a new model by allowing for a technology frontier displacement. The first approach implies that, in the space of efficiency levels of different inputs, there is a unique technology frontier, and all countries but the leader lie inside the frontier. Over the second half of the 20th century, the US economy has typically been the world technology leader. Then, it is assumed to be the country that defines the frontier. However, the evolution of the world technological frontier is not limited to single countries. So, we have decided to adopt the idea of a technology frontier as suggested by Jones (2005) and defined by Caselli - Colleman (2006). It is argued that a new invention is a draw from the distribution of possible (yet undiscovered) production functions. Therefore, a newly invented production function can be represented as a point in the technological space. At any given point in time, firms will choose their production function from this set of feasible possibilities. ${ }^{3}$

Our paper contains various innovative approaches. First, although inspired by Acemoglu et al. (2006), it departs from that work on several counts. Specifically, we address the question of how the definition of technological frontier determines a change in the effects of $R \& D$ activities on productivity growth for a set of leading economies - the US and leading European countries. To this end, we compare two possible different model specifications. In the first one, the technological frontier position is determined by the country with the highest productivity for the period considered, in this case, the United States. Alternatively, in the second specification, we alter the definition of the technological frontier, allowing for a shift. To the best of our knowledge, our study is the first to adopt such specification to explain to what extend alterations in the technology frontier influences the effects of adoption of technology versus innovation on productivity growth. Second, our paper evidences that the parameters of the $R \& D$ technology differ across nations, and this is what delivers differences in the results. Third, our innovation-imitation framework nests the R\&D growth models for countries close to or in the frontier that mainly innovate, and those using less-than-best-practice technologies are pushed to basically imitate. Fourth, on the empirical side, our proposed model of endogenous technology finds evidence of productivity growth on both innovation and technology transfer. Our findings suggest that the pattern of technology development is sensitive across definitions of technology frontier and to alternative functional forms.

Another set of literature, e.g. Hidalgo et al. (2007) and Liu (2007), explore how countries use the technology, capital, institutions, and human capital to develop new, more sophisticated goods that are close to the ones that have been produced before. The authors develop the idea of product upgrade in which network representations are used to visualise proximities among the products that countries export and their evolution. 
The rest of the paper is organised as follows. Section 2 lays out the basic structure of the innovation-imitation model. Section 3 presents the empirical analysis, which includes a brief review of the data and the definition of variables. Section 4 contains the estimated results based on the two different scenarios proposed. Section 5 presents the main implications and Section 6 concludes.

\section{THEORETICAL FRAMEWORK}

The economy consists of identical agents that produce a final good using the classical inputs and knowledge (A). The agents can be engaged in both the production of the final good and in the R\&D sector. Final good produced at time $t$ is given by:

$$
Y_{t}=A_{t}^{\sigma} K_{t}^{\alpha} L_{Y t}^{1-\alpha}
$$

where $K_{t}$ is physical capital, $L_{Y t}$ is the total quantity of human capital employed to produce output, and $A_{t}$ is an index of technical efficiency. ${ }^{4}$ We assume that population grows exogenously at rate $n>0,0<\alpha<1$ and $\sigma>0$.

Technology improvement results from a combination of two sources: imitation activities by adopting the ones already discovered (coincident with the leader's technological frontier) and a country's own discoveries. Accordingly, the technological level of the economy depends on the number of researchers engaged in innovation and/or in imitation activities, as well as the country's level of technology relative to the level of what we consider world knowledge $\left(\mathrm{A}^{*}\right)$ :

$$
A_{t+1}=\left[\delta L_{A t}^{\lambda} A_{t}\right]^{\varphi_{1}}\left[\mu L_{A t}^{\lambda}\left(A_{t}^{*} / A_{t}\right)\right]^{\varphi_{2}},
$$

where the dependent variable $A_{t+1}$ is the knowledge stock in $t+1$, and $L_{A t}$ represents employment in the R\&D sector (it is worth noting that $L_{A t}+L_{Y t}=L_{t}=L_{0} \exp (n t)$ )). The sensitivity of knowledge to the research structure in innovation and diffusion processes, respectively, is represented by the parameters $\varphi_{1}, \varphi_{2} \in(0,1)$, and $\delta, \mu \in(0,1)$.

Equation (2) grows in its arguments and captures the two dimensions of technological progress. One source of such progress comes from research activities

$4 \quad$ Notice that there are constant returns to scale in $K$ and $L_{Y t}$, holding $A$ constant, and increasing returns to $K, L_{Y}$, and $A$ together. This assumption reflects the now common notion that ideas are non-rival or infinitely expansible. 
and it is based on the local technology system (the first term on the right hand side of the equation). The existence of decreasing returns from the scientific community in terms of new ideas is captured by $0<\lambda<1$. Moreover, the work of some researchers also involves adapting technologies at the frontier, which is shown in the last term of equation (2). This element captures the capacity of a country to imitate, as a function of the work done in the R\&D sector, and it is also related to a catching-up term, represented by $A_{i}^{*} / A_{i}$. The distance to the frontier is used to capture the potential for technology transfers. The knowledge stock at a moment in time, and in a particular country, is considered as a weighted geometrical average of the knowledge generated by both processes in the past. The fact that $\lambda, \varphi_{1}$ and $\varphi_{2}$ may be different allows for a technology adoption process to occur when innovation happens together with imitation. Additionally, the process could also differ across countries.

One interesting feature about equation (2) is its flexibility to transform into different specifications. Indeed, if we impose some restrictions, such as $\varphi_{2} \rightarrow 0$ for firms at the technological frontier, it becomes:

$$
A_{t+1}=\left[\delta L_{A t}^{\lambda} A_{t}\right]^{\varphi_{1}} .
$$

The only source of knowledge for these countries will be the generation of new ideas. However, for economies immersed in a more basic research stage (below the technological frontier), we could consider the parameter $\varphi_{1} \rightarrow 0$, and then equation (2) could be transformed into:

$$
A_{t+1}=\left[\mu L_{A t}^{\lambda}\left(A_{t}^{*} / A_{t}\right)\right]^{\varphi_{2}} .
$$

In this case, the only source of knowledge for these countries will be the imitation of ideas generated at the frontier. Additionally, a wide range of intermediate situations between the two extremes - represented by equations (3) and (4) - could be considered. Thus, when the constraint $\phi_{1}+\phi_{2}=1$ is imposed, equation (2) is reduced to:

$$
A_{t+1}=\left[\delta L_{A t}^{\lambda} A_{t}\right]^{\gamma}\left[\mu L_{A t}^{\lambda}\left(A_{t}^{*} / A_{t}\right)\right]^{1-\gamma},
$$

where $\gamma \in(0,1)$ represents the technology share. The constraint imposes constant returns to scale in the Cobb-Douglas production function for TFP in period $t+1$.

We solve for the growth rate of knowledge by noting that it is constant at the balanced growth path. Taking logarithmic and derivatives in equation (2), we obtain the growth rate of the knowledge stock: 


$$
\bar{g}_{A}=\lambda\left\{\left(\varphi_{1}+\varphi_{2}\right) n+\left[\varphi_{2} /\left(1-\varphi_{1}\right)\right] n^{*}\right\} /\left(1+\varphi_{2}-\varphi_{1}\right)
$$

where $n^{*}, n$ are the exogenous growth rates of labour in the leading and following countries, respectively. We can then easily get the steady-state growth rate for a follower country from equation (5) as:

$$
\bar{g}_{A}=\lambda\left(n+n^{*}\right) / 2(1-\gamma),
$$

which, in the case of the leader, becomes

$$
\bar{g}_{A^{*}}=\lambda n^{*} /(1-\gamma)
$$

An interesting derivation from equations (6) to (8) would be that the long-run growth rate does not depend on the number of researchers. It is determined by the elasticity of the knowledge's function and by the population growth rate.

Parameters $\delta$ and $\mu$ are related to social infrastructures and any other additional factors, which can contribute to an improvement in the country's technological level. In order to understand its role, we focus on the equation below, that can be obtained from equation (4):

$$
\frac{A^{*}}{A}=\frac{A}{L_{A}^{\lambda}} \cdot \frac{1+\bar{g}_{A}}{\mu} .
$$

The dynamic of $\frac{A^{*}}{A}$ depends on $\frac{1+\bar{g}_{A}}{\mu}$. Other things equal, when parameter $\mu$ is large, then the country's distance to the frontier is small and vice versa.

\section{VARIABLES AND DATA DESCRIPTION}

We applied our main theoretical framework to four countries: the United States and three leading European countries (France, Germany, and the United Kingdom) over the period 1950-2001. The yearly data used in the empirical application come from a number of sources (see Appendix 1 for details). The main features about the data and the construction of variables are described in this section. ${ }^{5}$

5 A possible objection is that we have used yearly data, instead of the mean for a group of years to avoid business cycle dynamics. We have adopted this approach following Jones (2002a) and Papageorgiou (2003) with the aim of gaining more degrees of freedom, a relevant matter in panel data analysis. It should be noted from Figure 2 that the TFP growth rates among the countries in our sample have been surprisingly stable over the period. 
For the accounting exercise that follows, we need to derive several results from Jones' (2002) setup. First, the production function in equation (1) can be rewritten in terms of output per worker, $y_{t}=Y / L_{t}$ as:

$$
y_{t}=\left(K_{t} / Y_{t}\right)^{\frac{\alpha}{1-\alpha}} l_{Y_{t}} h_{t} A_{t}^{\frac{\sigma}{1-\alpha}}
$$

where $Y_{t}$ represents the production of goods and services, $K_{t}$ is the stock of physical capital, $l_{Y_{t}}$ is the proportion of the workforce allocated in the production of goods, $h_{t}$ is human capital per capita, and $A_{t}$ is the stock of knowledge available in the economy. $A$ is measured by TFP and derived from equation (10) in the same spirit as Solow's classic growth accounting model, under the following assumption: the elasticity of capital with respect to income $\alpha$ is assumed to be equal to one-third, in line with the most representative literature (Mankiw 1995; Gollin 2002).

Writing the labour-force data constraint as $L_{Y t}+L_{A t}=L_{t}$ could be useful at this point, where $L_{t}$ denotes total employment, $L_{Y t}$ is the amount of labour producing output, and $L_{A t}$ is the number of researchers and scientists. In addition, we define $l_{Y}=L_{Y} / L$ and $l_{A}=L_{A} / L$ as the fraction of labour employed producing output and producing ideas, respectively. As a result, $l_{Y t}=\left(1-l_{A t}\right)$. The next step is to obtain values for the education parameters. In this paper, education attainment has been measured by the average years of schooling for individuals aged 25 and over. Following Hall - Jones (1999), this turned into a measure of $h$ through the specification $h_{t}=\exp \left(\psi l_{h t}\right)$, which assumes that the endowment of human capital per person depends on the time devoted to training $\left(l_{h t}\right) \cdot{ }^{6}$ Mincer's (1974) results on the return on education suggest a value of $\psi=0.07$. It implies that an additional year of schooling has a direct effect of raising labour productivity by seven percent. The last term in equation (10) is the knowledge stock, calculated as TFP. To provide a rough empirical measure of this variable, we make the normalisation $\sigma=(1-\alpha)$, so that $A$ is measured in units of Harrod-neutral productivity. This measure of TFP is given by:

$$
A_{t}=y_{t}\left[\left(K_{t} / Y_{t}\right)^{1 / 2}\left(1-l_{A t}\right) e^{0.07 * l_{h t}}\right]^{-1} .
$$

In order to illustrate the evolution of main variables involved, Table 1 provides an overview of the labour productivity, research intensity, and TFP by country in 1950 and 2001. Figure 1 plots GDP per hour worked as a proxy for the labour productivity. The US shows an upward sloping trend, with a substantial gap from

6 A similar approach can be found in Máté (2015). 
the time trend evolution line for the selected European countries. As it can be observed, the European countries have experienced a higher growth rate than the US over the period, especially since the beginning of the 1980s.

\section{Table 1}

Descriptive analysis

\begin{tabular}{lccccc}
\hline & Year & Germany & France & UK & US \\
\hline GDP per hour & 1950 & 4.0 & 4.4 & 5.4 & 14.4 \\
& 2001 & 27.9 & 25.6 & 17.3 & 40.0 \\
Research intensity & 1950 & 0.08 & 0.08 & 0.10 & 0.27 \\
& 2001 & 0.85 & 0.74 & 0.58 & 1.00 \\
TFP & 1950 & 1.3 & 1.7 & 2.6 & 4.6 \\
& 2001 & 6.6 & 6.6 & 4.8 & 9.8 \\
\hline
\end{tabular}

Source: Author's elaboration.

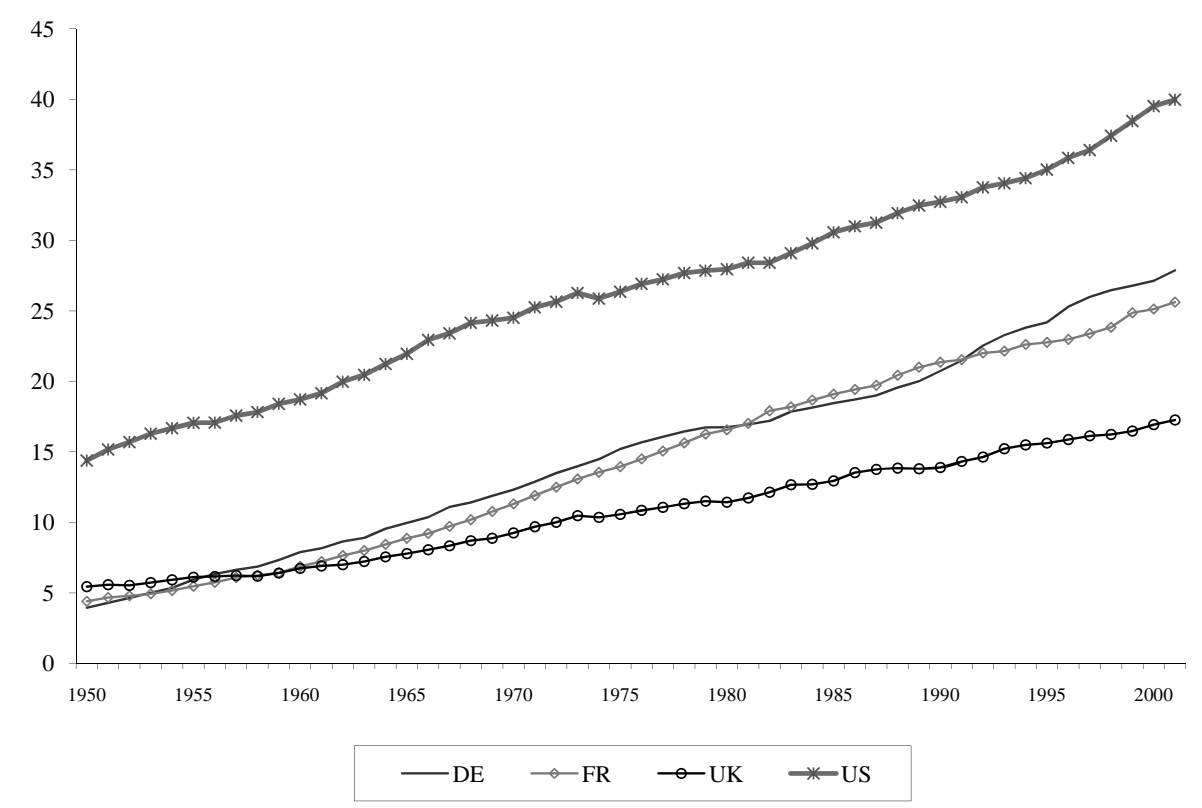

Figure 1. Real output per hour in international dollars (i.e in PPP 1990) 


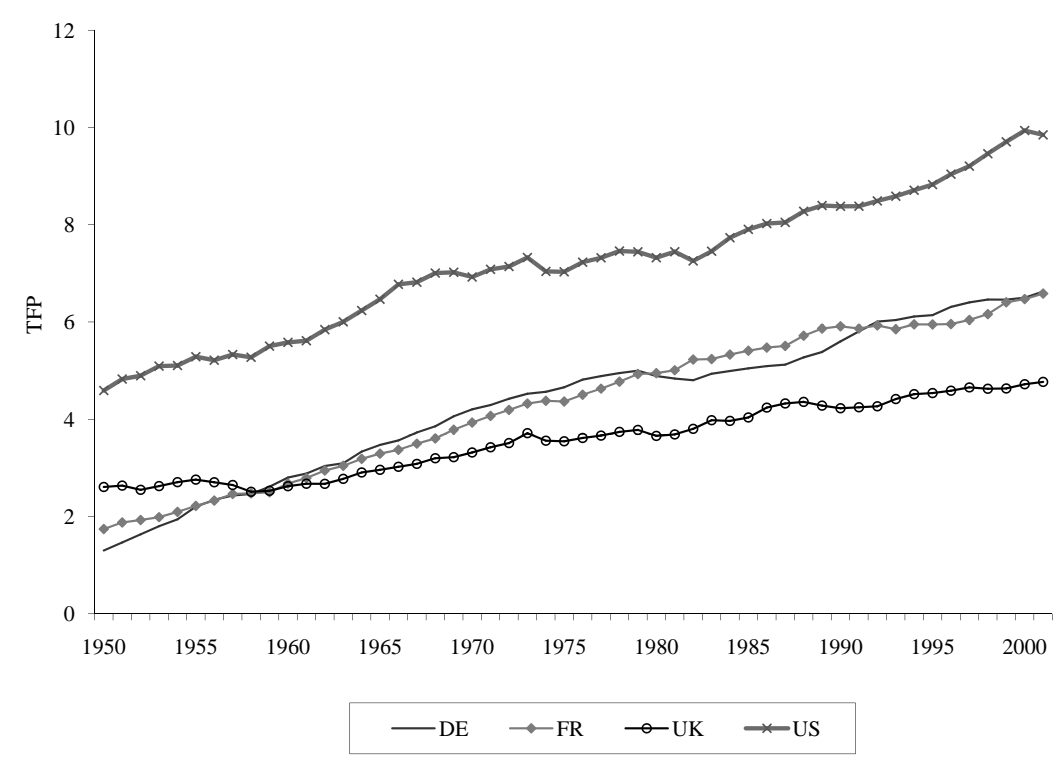

Figure 2. Total factor productivity

Regarding the interpretation of equation (11), the number of researchers and scientists share engaged in $R \& D$ is used to capture research intensity related to employment $\left(l_{A}\right)$. Between 1950 and 2001, it increased by a factor of 10 in Germany and France, and by a factor of five in the US and the UK. The US accounts for the highest research intensity during the sample period, although Germany rose up to 85 percent relative to the US in 2001. These rates reflect the very rapid growth in the number of researchers and scientists in technology leading countries.

Figure 2 plots the evolution of TFP. Germany and France experienced the fastest expansion of their TFP: more than fivefold and nearly fourfold, respectively. The United Kingdom experienced the smallest increase of only 80 percent, while the US doubled its TFP level.

\section{ESTIMATION RESULTS}

Once the different alternatives of the model have been constructed, we use panel data techniques to estimate equation (2), with special focus on the role of technology frontier. In this equation, the knowledge stock in $t+1$ could be expressed as a function of today's technological effort as well as a function that depends on the 
distance from the technology frontier. We consider two possible scenarios: first, the baseline scenario, in which the technological frontier is set up in the country with the highest TFP; second, the non-observable scenario, where the technology frontier shifts right and the leader country falls inside it.

\subsection{Baseline scenario: technological frontier's position on the US economy}

According to the data analysed in the above section, the US economy can be considered as the leader economy and, then, the technological frontier in this scenario will be referring to the US, $A_{t}^{*}=A_{t}^{U S}$. The distance from the technological frontier is defined as the ratio of the TFP for the US with respect to the one for the follower country. Taking logarithms in (2) and subtracting $a_{t}$ on both sides of the equation, a log-linear approximation of the productivity growth in a discretetime version can be obtained. The dynamics of TFP for a general case can be expressed as:

$$
\Delta a_{t+1}=c_{1}+\lambda\left(\varphi_{1}+\varphi_{2}\right) l_{t}+\left(\varphi_{1}-1\right) a_{t}+\varphi_{2}\left(a_{t}^{U S}-a_{t}\right)+\varepsilon_{t+},
$$

where $c_{1}=\left[\varphi_{1} \log (\delta)+\varphi_{2} \log (\mu)\right]$ is a constant, and $\varepsilon_{t+1}$ is a shock that is generated by a stationary process with zero mean. Equation (12) relates each country's technical progress positively to three components, namely research effort, country's level of technology, and the relative level of technology compared to the leader country. The last component refers to the catch-up term, i.e. a country's TFP adjusts towards the frontier at a rate of $\varphi_{2}$. If the value of this coefficient is high (and positive) the non-leader country will perform better when the distance increases. When the catching-up term approaches zero, the aggregate technology rate depends mainly on the binomial $\lambda \varphi_{1} l_{t}+\left(\varphi_{1}-1\right) a_{t}$. Being so, the country may increase its growth rate by increasing the number of researchers that work on innovation activities. This would mean that for the leader country equation (12) applies by eliminating the catching-up term.

Our main goal consists of estimating the values of the parameters of interest: $\lambda$, $\varphi_{1}$ and $\varphi_{2}$. The first coefficient represents the researcher performance, the second the effect of old ideas on new ones, and the third the convergence rate. The parameters can be estimated using ordinary least square (OLS), obtaining consistent but not efficient estimations, or the maximum likelihood estimator (MLE) under the assumption that errors are normally distributed. As the TFP term is included in the right hand side of equation (12), we need instrumental variables (IVs) to estimate it. The optimal Generalised Method of Moments (GMM) estimator is derived by minimising the GMM objective function with the optimal choice of the matrix of instruments. 
Table 2

Baseline model

Dependent variable is $\Delta \log (\mathrm{TFP})$

Estimation method: GMM

\begin{tabular}{lcccc}
\hline Coefficients & Germany & France & UK & US \\
\hline$c_{1}$ & -0.144 & -0.002 & $-0.176^{*}$ & -0.051 \\
& $(0.07)$ & $(0.06)$ & $(0.09)$ & $(0.04)$ \\
$\lambda\left(\varphi_{1}+\varphi_{2}\right)$ & 0.010 & -0.008 & 0.023 & $0.063^{* * *}$ \\
& $(0.01)$ & $(0.03)$ & $(0.03)$ & $(0.02)$ \\
$\varphi_{1}-1$ & 0.018 & 0.016 & -0.045 & $-0.171^{* * *}$ \\
& $(0.06)$ & $(0.09)$ & $(0.06)$ & $(0.06)$ \\
$\varphi_{2}$ & $0.185^{* * *}$ & 0.067 & $0.201^{* * *}$ & \\
& $(0.07)$ & $(0.08)$ & $(0.09)$ & \\
$\lambda$ implicit & & & & $0.075^{* * *}$ \\
& & & & $0.03)$ \\
$\mathrm{R}^{2}$ & 0.70 & 0.40 & 0.18 & 0.21 \\
$\mathrm{DW}$ & 1.87 & 1.89 & 1.88 & 2.18 \\
\hline
\end{tabular}

Notes: Standard errors are in parenthesis and are robust to heteroscedasticity and autocorrelation according to Newey-West correction of standard errors. ***,** and * indicate statistical significance at the levels of 1,5 and $10 \%$, respectively. The standard error of $\lambda$ implicit in the US was calculated by the delta method.

As indicated above, in order to address the possible existence of endogeneity, we have used the lagged levels of the variables as instruments, which we assume are uncorrelated with $\varepsilon_{t+1}$. We estimated the equation by applying GMM, which displays robust estimators to the presence of heteroscedasticity and autocorrelation. After completing the steps above, we have the best approach to the technology growth equations specified in the above sections. Results for the baseline model are reported in Table 2, which offers a fairly satisfactory explanation of the way technological progress evolves. The coefficients for the US economy, $\lambda$ implicit and $\left(\varphi_{1}-1\right)$, have the correct sign and the values suggest that there is a positive relationship between researcher's effort and TFP growth, a circumstance that is not clearly appreciable in European countries (similar results were obtained by Jones 2002; Myro et al. 2008; Perez et al. 2011). The results also show a positive relationship between the distance to the frontier and the growth rate of TFP in Germany and the UK (not in the case of France) with values for the parameter $\varphi_{2}$ of 0.185 and 0.201 , respectively.

As we assume that all countries have access to the technology frontier, firms can engage in both development and adoption of new process and products. The model specified in equation (5) can be constrained, and so equation (12) transforms into: 


$$
\Delta a_{t+1}=c_{2}+\lambda l_{t}+2(\gamma-1) a_{t}+(1-\gamma) a_{t}^{U S}+\varepsilon_{t+1},
$$

where $c_{2}=[\gamma \log (\delta)+(1-\gamma) \log (\mu)]$ is a constant. The results are presented in Table 3, which in the case of the US economy are mostly similar to those shown previously in Table 2. Firstly, the researcher's performance captured by $\lambda$ has the expected sign and it is significant at conventional levels for Germany, the UK, and the US. Secondly, the magnitude of the coefficients implies that the US performance (0.063) is larger than that of the European countries by a factor of 1.5. Additionally, the technology share $(\gamma)$ enters positively and it is significant at the $1 \%$ level. In other words, more than 80 percent of the R\&D labour force is concentrated in the innovating sector.

Table 3

Baseline constrained model

Dependent variable is $\Delta \log (\mathrm{TFP})$

Estimation method: GMM

\begin{tabular}{lcccc}
\hline Coefficients & Germany & France & UK & US \\
\hline$c_{2}$ & $-0.075^{*}$ & 0.055 & $-0.011^{*}$ & -0.051 \\
$\lambda$ & $(0.04)$ & $(0.04)$ & $(0.06)$ & $(0.04)$ \\
& $0.039^{* * *}$ & -0.004 & $0.040^{* *}$ & $0.063^{* * *}$ \\
$\gamma$ & $(0.01)$ & $(0.01)$ & $(0.02)$ & $(0.02)$ \\
& $0.915^{* * *}$ & $0.983^{* * *}$ & $0.903^{* * *}$ & $0.829^{* * *}$ \\
$\mathrm{R}^{2}$ & $(0.01)$ & $(0.01)$ & $(0.03)$ & $(0.06)$ \\
$\mathrm{DW}$ & 0.70 & 0.37 & 0.14 & 0.21 \\
\hline
\end{tabular}

Note: $* * *, * *$ and $*$ indicate statistical significance at the levels of 1,5 and $10 \%$, respectively.

\subsection{Scenario 2: allowing for a technology frontier shift}

As regards the robustness of our model, a crucial implication is how sensitive the empirical outcomes are to the definition of the technology frontier. It is well known that an outward shift of the frontier might result from any increase in the inputs, other external factors or shocks, and from technological progress. Although the baseline specification assumes that the technological frontier refers to the US, the leader country may itself lie below the frontier. If this is the case, the function of productivity growth must be specified in terms of a non-observable component. According to the empirical evidence, the process must be specified as a random walk with a drift (or, alternatively, as an integrated process of second order). In this case, we have to consider a model with unobserved components. 
Therefore, equations (12)-(13) admit a transformation in a state space using Kalman's filter. In order to treat the evolution of the frontier specifically, those equations can be transformed in an augmented matrix with a random walk that admits a drift (as suggested by Harvey 1989 and Hamilton 1994). See Appendix 2 for the econometric specification using Kalman's filter.

The system of equations for the general model in a vector form is given by

$$
\begin{aligned}
& \Delta \mathbf{a}_{t+1}=c_{1}+\lambda\left(\varphi_{1}+\varphi_{2}\right) \mathbf{l}_{t}+\left(\varphi_{1}-\varphi_{2}-1\right) \mathbf{a}_{t}+\varphi_{2} \boldsymbol{\xi}_{t}+\mathbf{w}_{t+1} . \\
& \boldsymbol{\xi}_{t}=c_{2} \boldsymbol{\xi}_{t-1}+\boldsymbol{\beta}+\mathbf{v}_{t}
\end{aligned}
$$

Incorporating the parameters constraint $\left(\varphi_{1}+\varphi_{2}=1\right)$, the system of equations yields to:

$$
\begin{aligned}
& \Delta \mathbf{a}_{t+1}=c_{1}+\lambda \mathbf{l}_{t}+2(\gamma-1) \mathbf{a}_{t}+(1-\gamma) \xi_{t}+\mathbf{w}_{t+1} . \\
& \boldsymbol{\xi}_{t}=c_{2} \boldsymbol{\xi}_{t-1}+\boldsymbol{\beta}+\mathbf{v}_{t}
\end{aligned}
$$

While the first equation of systems (14) and (15) defines the technology progress, the second equation captures the evolution of the frontier. This evolution is assumed to follow an AR(1) process with a constant mean - as the shocks affecting the random coefficients, although quite persistent, eventually return to their mean values. The parameters of both systems of equations are estimated by MLE, under the assumption that the distribution of $\Delta \boldsymbol{a}_{t+1}$ follows a multivariate normal process that depends on the value of $\boldsymbol{l}_{t}$ and $\boldsymbol{a}_{\boldsymbol{t}}$ and its own past value. Under regularity conditions, the MLE behaves as asymptotically efficient (Green 2003).

Table 4 reports the MLE estimates for the model specified by (14), which roughly differ from the GMM estimation (Table 2). In this second scenario, when a displacement in the technological frontier occurs, parameter $\lambda$ increases its magnitude for the US economy, although it is no longer significant. A second difference accounts for $\varphi_{1}$ (country's level of technology); its influence on knowledge growth being highly significant, ranging from 0.56 for the US to 0.88 for France. The parameter that stands for imitation $\left(\varphi_{2}\right)$ exerts no influence.

With respect to the restricted system (15), Table 5 offers a different picture from Table 3. First, the estimation on researchers' performance becomes significant and larger than when the technological frontier lied on the US economy. From a comparison of Tables 3-5, it follows that researchers from both the US and the UK would produce, on average, three times more knowledge than what they did in the baseline scenario (i.e. $0.168 v s .0 .063$ and $0.119 v s .0 .040$, respectively). Moreover, the results for Germany indicate that the new $\lambda$ parameter is six times higher (i.e. $0.227 v$ s. 0.039). Second, the technology shares are now broadly similar ( $\gamma$ around 0.8 ) and highly significant across countries. In sum, as- 
suming that the technology frontier transcended the leader country, inventiveness performance increases for all the sample countries, and differences between them are reduced to the bare minimum (except for France). ${ }^{7}$

Table 4

State space model

Dependent variable is $\Delta \log (\mathrm{TFP})$

Estimation method: MLE

\begin{tabular}{lcccc}
\hline Coefficients & Germany & France & UK & US \\
\hline$\lambda$ & 0.081 & 0.028 & 0.032 & 0.205 \\
& $(0.07)$ & $(0.05)$ & $(0.05)$ & $(0.16)$ \\
$\varphi_{1}$ & $0.731^{* * *}$ & $0.881^{* * *}$ & $0.815^{* * *}$ & $0.555^{* * *}$ \\
& $(0.14)$ & $(0.10)$ & $(0.14)$ & $(0.17)$ \\
$\varphi_{2}$ & 0.001 & 0.001 & 0.001 & 0.001 \\
& $(0.00)$ & $(0.00)$ & $(0.00)$ & $(0.00)$ \\
\hline
\end{tabular}

Notes: Standard errors are given in brackets. ${ }^{* * *},{ }^{* *}$ and ${ }^{*}$ indicate statistical significance at the levels of 1,5 and $10 \%$, respectively.

\section{Table 5}

State space constrained model

Dependent variable is $\Delta \log (\mathrm{TFP})$

Estimation method: MLE

\begin{tabular}{lllll}
\hline Coefficients & DE & FR & UK & US \\
\hline$\lambda$ & $0.227^{* *}$ & $0.159^{* * *}$ & $0.119^{* * *}$ & $0.168^{* * *}$ \\
& $(0.07)$ & $(0.11)$ & $(0.04)$ & $(0.04)$ \\
$\gamma$ & $0.764^{* * *}$ & $1.188^{* * *}$ & $0.858^{* * *}$ & $0.796^{* * *}$ \\
& $(0.08)$ & $(0.18)$ & $(0.05)$ & $(0.05)$ \\
\hline
\end{tabular}

Notes: Standard errors are in parenthesis and are robust to heteroscedasticity and autocorrelation according to Newey-West correction of standard errors. ${ }^{* * *},{ }^{* *}$ and ${ }^{*}$ indicate statistical significance at the levels of 1,5 and $10 \%$, respectively.

7 Both specifications (14) and (15) include country-specific constants unreported that were never significant nor did they affect the substance of the residuals. 


\section{IMPLICATIONS}

To what extent do estimates depend on basic assumptions that are made in order to capture the notion of technological development? Table 1 displays the country's observed situation, revealing that European countries' relative position appears to be distant from the US frontier. ${ }^{8}$ The different specifications proposed in this study bring about important implications related to the sources of technology growth, more specifically, about researchers' performance - inventiveness -, diffusion of knowledge, and technology frontier. We now use the regression results to see how well the model fits the experience of the countries included in the sample.

What do our results imply about researcher performance in terms of inventiveness? With the estimates from the constrained model in hand, we can turn to counterfactual calculations, in the spirit of Caselli - Colleman (2006). Then, in order to assess the quantitative importance of invention, we ask the following question: holding the US technology frontier constant, by how much would a country's TFP change if we increased researcher's abilities at innovating? We compute the levels of TFP associated with a specific shock on inventiveness. Finally, we compare these numbers with both the country's actual values and the ones corresponding to the US. In other words, we assess the knowledge consequences of movements along a given technology frontier. Hence, we simulate this counterfactual for Germany.

Table 3 shows that researcher performance is $50 \%$ higher in the US than in Germany and the UK. To better understand the importance of these differences, we have simulated how changes in $\lambda$ influence the transitional growth path in Germany. The result of this experiment is plotted in Figure 3. As can be seen, a uniform increase of $5 \%$ in $\lambda$ works out in a higher growth path, which in turn leads to a higher TFP steady-state than the actual path. The extrapolated German knowledge tends to catch up with that of the US, ceteris paribus. We interpret this finding as indicating that enhancing researcher's performance could play a central role in determining knowledge differences across countries.

As regards the diffusion of knowledge, an important question arises: why European countries do not devote more $R \& D$ endowments to transfer technology if its contribution to the growth of knowledge growth is large? One plausible explanation, given our results, is that in non-integrated markets, researchers might engage in both $R \& D$ activities, thus, the innovation imitation ratio might not re-

Note, for example, that Germany's TFP in 2001 was two-thirds of that in the US. 


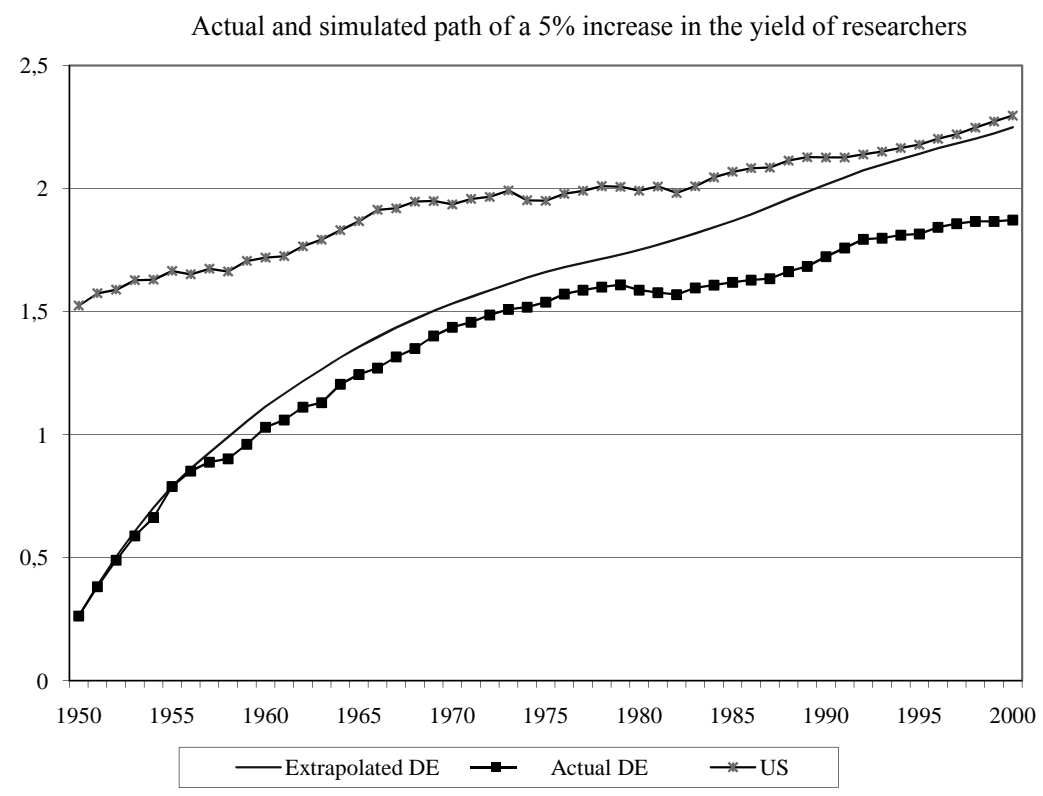

Figure 3. Germany: TFP catching up with the US frontier

spond to the productivity criteria. As a result, the potential technological growth rate would decrease. ${ }^{9}$

Next, we turn to a quantitative assessment of the technology frontier shift. Our findings suggest that the pattern of technology development is sensitive across definitions of the technology frontier. If we compare results across Tables 3 to 5 , we see that there is an increase in the generation of new ideas across countries, when considering a complex world technology frontier.

With the estimates from the constrained models, we can address what would happen in the long run if we considered both a country leader and a world menu of best practice technologies? Hence, we now compare each country's observed steady-state growth rate with the steady-state growth rate that the country would obtain if it had access to the world technology frontier. For this experiment, we assume a constant population growth rate of $1.6 \%$ for the US, and $0.5 \%$ for European countries, which are the real growth rates on employment over the sample

9 Van Ark et al. (2008) highlighted the idea of how the benefits of knowledge differ greatly between advanced economies and that led to differences in productivity in the US economy and some European countries. They emphasised the role that labour markets and the high level of product market regulations played in Europe. As a residual measure, TFP might reflect the overall efficiency of the production process, which may include the impact of organisational changes related to the use of information technology. 
period. It does not come as a surprise that in the result from equation (8), American researchers' performance on the steady-state rises significantly, from $0.59 \%$ to $1.32 \%$. These figures show the substantial influence of a technology frontier drift in which the steady-state growth rate could increase by up to twofold. It should be clear from equation (7) that the impact for European countries would be even greater. Note that for the UK, the steady-state growth rate boosts by up to fourfold, and for Germany it is multiplied by sixteen. Obviously, the steady state-growth rates could be lower in the future if population growth rates decline. However, it is important to note that the ratio between productivity growth rates for both scenarios, i.e. state space and baseline, remains unchanged.

\section{CONCLUSIONS}

The aim of this paper is to disentangle the effects of imitative and innovative research effort on technology growth. It starts with a R\&D technology model similar to Jones' (1995), that includes imitation efforts in which two scenarios are considered: in the baseline one, the US is located at the technology frontier; in the second one, the technology frontier is unknown. The empirical application to the model is carried out for four countries over 50 years by using panel data analysis and Kalman's filter techniques.

The analysis of two different scenarios, altering definitions of technological frontier, generates very different outcomes. In the baseline scenario, American researchers are more growth enhancing than their European counterparts and exhibit a better performance. One implication of our results is that the other countries could benefit from the spillovers, through technological diffusion of knowledge. In the second scenario - the technology frontier can transcend the limit imposed by the economy with the highest productivity (US) -, the results suggest that the spillover effects from innovation are greater by boosting the overall innovation performance. Additionally, dispersion among countries has been reduced.

These findings call for a more general definition of technology frontier, which is not limited to single countries. The points allocated within the frontier line would represent a menu of best practice technologies. Along the frontier, countries could alter the intensity in which different inputs are used. The traditional view that there is a unique technology frontier and all countries but the leader lie inside the frontier is overly simplistic. Instead, the data would be better rationalised if it were considered that at each point in time firms have access to a whole menu of best practice technologies; some of these technologies could be complemented either with imitative activities and/or with R\&D activities. 
The framework developed in this paper could be extended in a number of directions. First, it would be motivating to explore the explanation power of the analysis taking breakthrough innovations into consideration. In this regard, it should be useful to distinguish between normal technical progress and technical progress associated with new paradigms. Second, it might prove helpful to differentiate between public and private research, and the way they could induce knowledge. The appropriability of the economic returns from innovation clearly relates to the latter. Third, European countries devote to innovation more resources and similar number of scientists and researchers than the US. However, their achievement is not up to the American standard. These results show that there is still an open line for future work to analyse the role of social infrastructure, extensive scientific networks, and human capital in this framework.

\section{REFERENCES}

Acemoglu, D. - Aghion, P. - Zilibotti, F. (2006): Distance to Frontier, Selection and Economic Growth. Journal of the European Economic Association, 4(1): 37-74.

Aghion, P. - Howitt, P. (1992): A Model of Growth through Creative Destruction. Econometrica, 60: $323-351$.

Aghion, P. - Howitt, P. (2009): The Economics of Growth. Cambridge, MA.: MIT Press.

Astorga, P. - Fitzgerald, V. - Berges, A.R. (2011): Productivity Growth in Latin America over the Long Run. Review of Income and Wealth, 57(2): 203-223.

Barro, R.J. (2001): Human Capital and Growth. American Economic Review, 91(2): 12-17.

Benhabib, J. - Spiegel, M. (2005): Human Capital and Technology Diffusion. In: Aghion, P. - Durlauf, S. (eds): Handbook of Economic Growth, Volume 1, Chapter 13, pp. 935-966.

Caballero, R.J. - Jaffe, A.B (1993): How High is the Giants' Shoulders? An Empirical Assessment of Knowledge Spillovers and Creative Destruction in a Model of Economic Growth. In: Blanchard, O.J. - Fisher, S. (eds): NBER Macroeconomics Annual. Cambridge: MIT Press, pp. $15-86$.

Caselli, F. - Colleman, W. (2006): The World Technology Frontier. American Economic Review, 96(3): 499-522.

Ciccone, A. - Papaioannou, E. (2009): Human Capital, the Structure of Production, and Growth. The Review of Economics and Statistics, 91: 66-82.

Coe, D.T. - Helpman, E. (1995): International R\&D Spillovers. European Economic Review, 39: 859-887.

De la Fuente, A. - Doménech, R. (2006): Human Capital in Growth Regressions: How Much Difference does Data Quality Make? Journal of the European Economic Association, 4(1): 1-36.

Eaton, J. - Kortum, S. (1996): Trade in Ideas. Patenting and Productivity in the OECD. Journal of International Economics, 40(3-4): 251-278.

Fagiolo, G. - Dosi, G. (2003): Exploitation, Exploration and Innovation in a Model of Endogenous Growth with Locally Interacting Agents. Structural Change and Economic Dynamics, 14(3): 237-273.

Galor, O. (2010): Comparative Economic Development: Insights from Unified Growth Theory. International Economic Review, 51(1): 1-44.

Gollin, D. (2002): Getting Income Shares Right. Journal of Political Economy, 110: 458-474. 
Green, W.H. (2003): Econometric Analysis. (Fifth ed.) New Jersey: Prentice Hall.

Griffith, R. - Redding, S. - Van Reenen, J. (2004): Mapping the Two Faces of R\&D: Productivity Growth in a Panel of OECD Industries. The Review of Economics and Statistics, 86(4): 883-895.

Griliches, Z. (1994): Productivity, R\&D, and the Data Constraint. American Economic Review, 84: $1-23$.

Grossman, G.M. - Helpman, E. (1991): Innovation and Growth in the Global Economy. Cambridge, MA: MIT Press.

Ha, J. - Howitt, P. (2006): Accounting for Trends in Productivity and R\&D. Journal of Money, Credit, and Banking, 39: 733-774.

Hall, R.E. - Jones, C.I. (1999): Why do Some Countries Produce So Much More Output per Worker than Others? The Quarterly Journal of Economics, 114: 83-116.

Hamilton, J.D. (1994): State Space Models. In: Engle, R.F. - McFadden, D.L. (eds): Handbook of Econometrics, Volume 4, Chapter 50. Amsterdam: Elsevier Science, 3039-3080.

Harvey, A.C. (1989): Forecasting, Structural Time Series Models and the Kalman Filter. Cambridge: University Press.

Hidalgo, C.A. - Klinger, B. - Barabási, A.L. - Hausman, R. (2007): The Product Space Conditions the Development of Nations. Science, 317: 482-487.

Jones, C.I. (1995): R\&D-Based Models of Economic Growth. Journal of Political Economy, 103(4): 759-784.

Jones, C.I. (2002): Sources of U.S. Economic Growth in a World of Ideas. American Economic Review, 92(1): 220-239.

Jones, C.I. (2005): The Shape of Production Functions and the Direction of Technical Change. Quarterly Journal of Economics, 120(2): 517-549.

Lazer, D. - Friedman, A. (2007): The Network Structure of Exploration and Exploitation. Computer and Information Science Faculty Publications, 52(4): 667-694.

Levinthal, D.A. - March J.G. (1981): A Model of Adaptive Organizational Search. Journal of Economic Behaviour and Organization, 2: 307-333.

Liu, J. (2007): Network Modeling of Product Space and Transformations. Science, online version.

Maddison, A. (1995a): Monitoring the World Economy, 1820-1992. Paris: OECD.

Maddison, A. (1995b): Explaining the Economic Performance of Nations: Essays in Time and Space. Aldershot: Edward Elgar Publishing.

Mankiw, N.G. (1995): The Growth of Nations. Brooking Papers on Economic Activity, 1: 275-310.

Máté, D. (2015): Impact of Human Capital on Productivity Growth in Different Labour-Skilled Branches. Acta Oeconomica, 65(1): 51-67.

Mincer, J. (1974): Schooling, Experience and Earnings. New York: Columbia University Press.

Myro, R. - Perez, P. - Colino, A. (2008): Economic Growth in a World of Ideas: The US and the Leading European Countries. Applied Economics, 40(22): 2901-2909.

Papageorgiou, C. (2003): Imitation in a Non-Scale R\&D Growth Model. Economic Letters, 80(3): 287-294.

Pérez, P. - Bengoa, M. - Fernández, A.C. (2011): Technological Capital and Technical Progress in the G-5 Countries. Journal of Applied Economics, XIV(2): 343-361.

Romer, P. (1990): Endogenous Technological Change. Journal of Political Economy, 98: 71-102.

Strulik, H. (2005): The Role of Human Capital and Population Growth in R\&D-Based Models of Economic Growth. Review of International Economics, 13(1): 129-145.

Tushman, M.L. - Anderson, P. (1986): Technological Discontinuities and Organizational Environments. Administrative Science Quarterly, 31(3): 439-465.

Van Ark, B. - O'Mahony, M. - Timmer, M. (2008): The Productivity Gap between Europe and the United States: Trends and Causes. Journal of Economic Perspectives, 22(1): 25-44. 


\section{APPENDIX 1: DATA SOURCES}

- GDP per hour. The data for GDP at 1990s constant prices were calculated using Eurostat (Statistical appendix to European Economy). The values corresponding to the period 1950-1960 are based on the GDP Movement Series provided by Maddison (1995a). Weekly working hours in non-agricultural activities were obtained from the Work Statistics Directories, published by the International Labour Organization (ILO), whilst it was necessary to use various issues of the OECD Labour Force Statistics in order to estimate some of the values for the United Kingdom.

- People in work. The starting point is the total employment in 1960, obtained from OECD Labour Force Statistics. The series for the following years were obtained by applying to that number the rates of variation provided by Eurostat. The series for the preceding years, 1950-1960, are calculated by deducting the annual variations provided by Maddison (1995a) from the number of people employed in 1960.

- Physical capital. Fixed capital stock was calculated by means of the perpetual inventory method, obtaining the initial value of capital stock following the approach of Harberger - Wisecarver (1977). The depreciation rate used was 4\%. For the years between 1950 and 1960, the annual variation rates provided by Maddison (1995b) were used to the value estimated for 1960.

- Investment. Gross Capital Investment at 1990 constant prices was calculated from Eurostat (European Economy Appendix). The values for 1950-1960 were calculated using the variation rates provided by Madison (1995b).

- Human capital. The data for average years of educational attainment for population over 25 years old come from De la Fuente - Doménech (2006).

- Engineers and scientists engaged in R\&D activities. The source (National Science Board and OECD) is the same as that indicated in Jones (2002), though it was necessary to estimate for 1994-1999 using the exponential smoothing method. For the years prior to 1960, it was assumed that the ratio of "research intensity" for each of the three European countries in relation to the US was the same in 1950 as in 1960. This ratio was interpolated for the intermediate years. The number of scientists and technicians was obtained from employment data. 


\section{APPENDIX 2: KALMAN'S FILTER METHODOLOGY APPLIED TO TECHNOLOGICAL FRONTIERS}

Let $Z_{1}, Z_{2}, \ldots, Z_{t}$ be the observations that account for the growth rate of the stock of ideas. They depend on another non-observable variable, the technological frontier, represented by $\xi_{t}$. The state space representation of the dynamics of an $(n \times 1)$ vector $Z$ is given by the following system of equations:

$$
\begin{aligned}
& \mathbf{Z}_{t}=A^{\prime} \mathbf{x}_{t}+H\left(z_{t}\right)^{\prime} \boldsymbol{\xi}_{t}+\mathbf{w}_{t} \\
& \boldsymbol{\xi}_{t}=F \boldsymbol{\xi}_{t-1}+\boldsymbol{\beta}+\mathbf{v}_{t}
\end{aligned}
$$

where $A^{\prime}, H^{\prime}$ and $F$ are matrixes of dimension $(n \times k),(n \times r)$ and $(r \times r)$, respectively, $x_{t}$ is a $(k \times 1)$ vector of exogenous or predetermined variables (the number of researchers and the stock of ideas), $\xi$ is a $(r \times 1)$ vector of unobserved state variables, $\beta$ is a $(r \times 1)$ vector of slopes, and the disturbance vectors $w$ and $v$ are assumed to be stationary and i.i.d, with $\operatorname{var}\left(w_{t}\right)=R, \operatorname{var}\left(v_{t}\right)=Q$ and $E\left(w_{s} v_{t}\right)=$ $0, \forall s, t$. The relation between $Z_{t}$ and $\xi_{t}$ is linear and specified by the first expression, which is known as the observation equation. The dynamic nature of the system is incorporated through the second equation, which is known as the state equation. In general, the elements of $\xi_{t}$ cannot be observed, but it is known that they can be generated by a first order Markov process. The parameter $\beta$ can be treated as part of the state vector, even though it is a constant, by defining the state vector as $\boldsymbol{\alpha}_{t}=\left[\boldsymbol{\xi}_{t}, \boldsymbol{\beta}_{t}\right]$ and letting the model be written in space state form as:

$$
\alpha_{t}=\left[\begin{array}{l}
\xi_{t} \\
\beta_{t}
\end{array}\right]=\left[\begin{array}{ll}
1 & 1 \\
0 & 1
\end{array}\right]\left[\begin{array}{l}
\xi_{t-1} \\
\beta_{t-1}
\end{array}\right]+\left[\begin{array}{l}
\eta_{t} \\
\zeta_{t}
\end{array}\right] .
$$

Under the hypothesis that the frontier does not coincide with the US, the main goal focus on estimating the parameters of interest and make inferences about $\boldsymbol{\xi}_{\tau}$, given observations of $\left(\boldsymbol{Z}_{\boldsymbol{t}}, \boldsymbol{x}_{t}\right)$ for $t=1,2,3, \ldots ., T$, using the Kalman's filter. 